\title{
Effect of the Surface Structure of $\operatorname{Pt}(100)$ and $\operatorname{Pt}(110)$ on the Oxidation of Carbon Monoxide in Alkaline Solution: an FTIR and Electrochemical Study
}

\author{
Paramaconi Rodríguez • Gonzalo García • \\ Enrique Herrero • Juan M. Feliu - Marc T. M. Koper
}

Published online: 21 June 2011

(C) The Author(s) 2011. This article is published with open access at Springerlink.com

\begin{abstract}
The electrochemical oxidation and infrared spectral features for carbon monoxide adsorbed on $\mathrm{Pt}(100)$ and $\mathrm{Pt}(110)$ in $0.1 \mathrm{M} \mathrm{NaOH}$ were studied as a function of the annealing/ cooling treatment with the objective to establish the influence of the platinum surface site geometry and the role of surface order in the electro-oxidation of $\mathrm{CO}$ on these two surfaces. Two common cooling methods ( $\mathrm{Ar}$ and $\mathrm{H}_{2} / \mathrm{Ar}$ atmospheres) were employed for both surface electrodes. Additionally, $\mathrm{CO}$ cooling and $\mathrm{I}_{2}$ vapour cooling methods were used for $\mathrm{Pt}(100)$ and $\mathrm{Pt}(110)$, respectively. Multiple CO vibration bands were observed on both electrode surfaces, their distribution and potential dependence strongly depending on the surface treatment.
\end{abstract}

Keywords Pt $(h k l) \cdot$ FTIR $\cdot \mathrm{CO}$ oxidation · Alkaline solution $\cdot$ Surface structure

P. Rodríguez $(\bowtie) \cdot$ G. García $\cdot$ M. T. M. Koper

Leiden Institute of Chemistry, Leiden University,

PO Box 9502, 2300 RA Leiden, The Netherlands

e-mail: rodriguezperezpb@chem.leidenuniv.nl

G. García

Departamento de Química Física,

Instituto Universitario de Materiales y Nanotecnología,

Universidad de La Laguna,

Astrofísico F. Sánchez s/n,

38071 La Laguna, Tenerife, Spain

E. Herrero · J. M. Feliu

Instituto de Electroquimica de la Universidad de Alicante, Apt. 99,

03080 Alicante, Spain

\section{Introduction}

The electrochemical adsorption/oxidation of $\mathrm{CO}$ has been one of the major subjects in fundamental and applied studies in the fields of electrocatalysis and electrochemical surface science because of the adverse effect of CO in lowtemperature fuel cells. Carbon monoxide oxidation is also used as a simple model reaction because $\mathrm{CO}$ acts as a neutral probe to surface activity and structure sensitivity.

Adsorption and electrooxidation of $\mathrm{CO}$ on platinum surfaces have been studied by several groups. Previous studies paid special attention to the surface structure and the effect of $\mathrm{pH}$ [1-9]. Several studies have been carried out to elucidate the kinetics and mechanism of the $\mathrm{CO}$ oxidation on platinum electrodes in acidic media $[1-4,6]$ as well in alkaline media [7-9]. Employing stepped electrodes, it was established that the $\mathrm{CO}$ oxidation reaction in acidic media takes place preferentially at step sites and that $\mathrm{CO}$ diffusion from the (111) terrace to these sites is very fast [1-4]. Surprisingly, in a recent work employing platinum stepped surfaces in alkaline media, four different active oxidation sites on the surface, i.e. sites with (111), (110) and (100) orientation, as well as kink sites were observed during $\mathrm{CO}$ stripping voltammetry $[8,9]$. The fact that, in alkaline media, the oxidation of $\mathrm{CO}$ can be observed on different sites was attributed to the blockage of the reactive step site by absorbed carbonate, which is the product of $\mathrm{CO}$ oxidation in alkaline media [8-10].

The electrooxidation of $\mathrm{CO}$ on $\mathrm{Pt}(100)$ and $\mathrm{Pt}(110)$ has received much less attention in comparison to $\mathrm{Pt}(111)$, especially in alkaline media. For these surfaces, it is well known that the conditions under which the crystal is cooled 
down to room temperature after the flame treatment have a strong effect on the crystalline order of the surface [11-17]. Previous studies showed that cooling down the surface in the absence of oxygen, i.e. in an $\mathrm{H}_{2} / \mathrm{Ar}$ atmosphere, is required for $\mathrm{Pt}(100)$ and stepped $\mathrm{Pt}$ surfaces [13-17] to obtain a well-ordered surface. It was also found by our group that different annealing procedures of the $\operatorname{Pt}(111)$ produce different surfaces with different $\mathrm{CO}$ vibrational signatures and CO oxidation behavior [18]. The effect of the annealing/cooling preparation on the surface structure of the $\operatorname{Pt}(110)$ surface has also been studied. The $\operatorname{Pt}(110)$ surface can exhibit two different superficial structures: $\operatorname{Pt}(110)-(1 \times 2)$ and $\operatorname{Pt}(110)-(1 \times 1)$. Bittner et al. showed by electrochemical scanning tunneling microscopy (EC-STM) that for a $\mathrm{Pt}(110)$ cooled in iodine, at very negative potentials (in $\mathrm{H}_{2} \mathrm{SO}_{4}$ solution), the iodine desorbs and gives rise to an unreconstructed $(1 \times 1)$ surface with a surface topography consisting of small rectangular and isotropic terraces [19]. However, as will be shown below, our results suggest the coexistence of both superficial structures $\mathrm{Pt}(110)-(1 \times 2)$ and $\operatorname{Pt}(110)-(1 \times 1)$, in better agreement with an older work from Vogel et al. [20].

In this paper, we present a study on the electrooxidation of $\mathrm{CO}$ on $\mathrm{Pt}(100)$ and $\mathrm{Pt}(110)$ single crystal electrodes in alkaline media. As in our previous study on the electro-oxidation of $\mathrm{CO}$ on $\mathrm{Pt}(111)$ [18], our experiments involved a combination of cyclic voltammetry and in situ Fourier transform infrared (FTIR) spectroscopy. The influence of different surface preparations of the $\mathrm{Pt}(100)$ and $\mathrm{Pt}(110)$ surface on the $\mathrm{CO}$ adsorption and oxidation will also be examined. This study was carried out in order to establish the influence of the platinum surface site geometry and the superficial order of these two surfaces on the electro-oxidation of $\mathrm{CO}$.

\section{Experimental}

For the electrochemistry experiments, bead-type single crystals of $\operatorname{Pt}(111), \operatorname{Pt}(100)$ and $\operatorname{Pt}(110)$ orientation prepared according to the method of Clavilier et al. [21] were used in this study. For the in situ infrared experiments, Pt disk electrodes (Mateck ${ }^{\circledR}$ ) of $1 \mathrm{~cm}$ diameter with the corresponding orientation were employed. Before each experiment, the single-crystal electrode was flame annealed and cooled down to room temperature according to the following methods:

1. Cooling down in an Ar atmosphere, after which the electrode was transferred to the cell under the protection of a droplet of de-oxygenated water

2. Cooling down in air and quenching with water after which the electrode was transferred to the cell under the protection of a droplet of water
3. Cooling down in an $\mathrm{H}_{2} / \mathrm{Ar}$ atmosphere, after which the electrode was transferred to the cell under the protection of a droplet of water saturated with the cooling gases.

4. Cooling down in an $\mathrm{CO} / \mathrm{Ar}$ atmosphere, after which the electrode was transferred to the cell under the protection of a droplet of water saturated with the cooling gases

5. Cooling down in an $\mathrm{I}_{2}$ atmosphere, after which the electrode was transferred to a first cell. In order to remove the $I_{2}$ from the surface, the electrode was immersed at controlled potential of $-0.1 \mathrm{~V}$ vs reversible hydrogen electrode (RHE). In order to avoid any contribution of the dissolved $\mathrm{I}_{2}$, the electrode was subsequently transferred to a second electrochemical cell with the working electrolyte.

In order to control the quality of the system, the blank voltammetric profile of the $\operatorname{Pt}(h k l)$ surface in $0.1 \mathrm{M} \mathrm{NaOH}$ was recorded before each experiment and compared with the literature [8, 21, 22]. CO stripping experiments were performed after bubbling $\mathrm{CO}$ through the cell for 2-3 min while keeping the Pt electrode at $0.05 \mathrm{~V}$, followed by argon purging for $20 \mathrm{~min}$ to remove the excess $\mathrm{CO}$ from solution. When the electrode was flame annealed and cooled down in a $\mathrm{CO} / \mathrm{Ar}$ atmosphere, the adsorbed $\mathrm{CO}$ was removed from the surface by stripping voltammetry and next readsorbed again by the procedure described above. All the CV stripping voltammograms shown here correspond to the stripping profile of the $\mathrm{CO}$ adsorbed in the electrochemical glass cell.

A Pt sheet was used as a counter electrode, and an RHE in the supporting electrolyte was employed as the reference electrode. Electrochemical measurements were performed with a computer-controlled Autolab PGSTAT12 potentiostatgalvanostat. The FTIR experiments were carried out with a Bruker Vertex $80 \mathrm{~V}$ Infrared spectrophotometer. A spectroelectrochemical glass cell with a $60^{\circ} \mathrm{CaF}_{2}$ prism was used, designed for the external reflection mode in a thin layer configuration. FTIR spectra were collected from an average of 20 scans obtained with $6 \mathrm{~cm}^{-1}$ resolution at selected potentials, by applying single potential steps from a reference potential $\left(E_{0}=0.05 \mathrm{~V}\right)$ in the positive-going direction up to $0.9 \mathrm{~V}$. Spectra are represented as the ratio $R /$ $R_{0}$, where $R$ and $R_{0}$ are the reflectance measured at the sample and the reference potential, respectively. Consequently, positive and negative bands correspond to the loss and gain of species at the sample potential, respectively. S- and p-polarised light were used to distinguish between adsorbed and solution species: s-polarised light probes only species in solution, whereas p-polarised light probes species on the electrode surface as well as in solution [23].

All glasswares were cleaned by boiling in concentrated sulfuric acid, followed by washing and boiling with ultra-pure water. Solutions were prepared from high purity reagents (99,998\%, Sigma-Aldrich) and ultra-pure water (Millipore 
MilliQ gradient A10 system, $18.2 \mathrm{M} \Omega \mathrm{cm}, 2 \mathrm{ppb}$ total organic carbon). Argon (N66) was used to deoxygenate all solutions and $\mathrm{CO}(\mathrm{N} 47)$ to dose $\mathrm{CO}$.

\section{Results and Discussion}

$\operatorname{Pt}(100)$

The blank voltammetric profiles of the $\mathrm{Pt}(100)$ electrode in alkaline media after different surface treatments are shown in Fig. 1. The cyclic voltammogram of the $\mathrm{Pt}(100)$ electrode recorded after cooling in a $\mathrm{H}_{2} / \mathrm{Ar}$ mixture (Fig. 1a) shows four well-defined quasi-reversible peaks that correspond to the adsorption/desorption process of $\mathrm{H}$ and $\mathrm{OH}$. Unfortunately and opposite to the case of the $\operatorname{Pt}(111)$, where it is possible to distinguish between the $\mathrm{H}_{\mathrm{ads} / \mathrm{des}}$ region and the $\mathrm{OH}_{\mathrm{ads} / \mathrm{des}}$, the discrimination between the $\mathrm{H}_{\mathrm{ads} / \mathrm{des}}$ and the $\mathrm{OH}_{\mathrm{ads} / \mathrm{des}}$ on the $\mathrm{Pt}(100)$ cannot be done in $0.1 \mathrm{M} \mathrm{NaOH}$ because of the overlapping peaks. It is important to note that the current densities of the four peaks are all similar. We will use the notation I, II, III and IV for these peaks, with peak I at the least positive potential ( $0.25 \mathrm{vs}$ RHE) and peak IVat the most positive potential ( $0.57 \mathrm{~V}$ vs RHE). Feliu et al. [13, 14], using ex situ STM, and Kibler et al. [15], using in situ STM, showed that when a $\mathrm{Pt}(100)$ electrode is cooled in a $\mathrm{H}_{2}$ containing atmosphere after flame-annealing, the surface presents flat terraces separated by monoatomic high steps and covered by monoatomically high square-shaped islands (Fig. 2). This result indicates that the reconstructed $\mathrm{Pt}(100)-$ hex $-\mathrm{R} 0.7^{\circ}$ (see Fig. 2), which is the stable surface in UHV, was lifted to a $\operatorname{Pt}(100)-(1 \times 1)$ surface during the cooling step.

The corresponding cyclic voltammogram of the Pt(100) cooled in $\operatorname{Ar}$ (Fig. 1b) is characterised by the same peaks IIV. However, the intensities of the peaks have changed, peak II now being more pronounced. This peak is expected to correspond to defect sites caused by the cooling step. This is in agreement with previous ex and in situ STM images, where the surface is covered by many small monotatomic islands making the surface rich in step and defect sites [13-15]. Tentatively, it was proposed that the formation of monoatomic islands originates from lifting of the thermally induced hex reconstruction and further roughening of the surface by oxygen adsorption present on the cooling system [15].

On the other hand, if the electrode is flame annealed and cooled down in a $\mathrm{CO} / \mathrm{Ar}$ saturated atmosphere (voltammogram shown in Fig. 1c), the changes with respect to the Fig. 1a are the opposite to those observed in Fig. 1b. Peaks I and II at lower potentials overlap and have low intensities in comparison with the peaks III and IV. The intensities of peaks III and IVare higher than in the case of the electrode
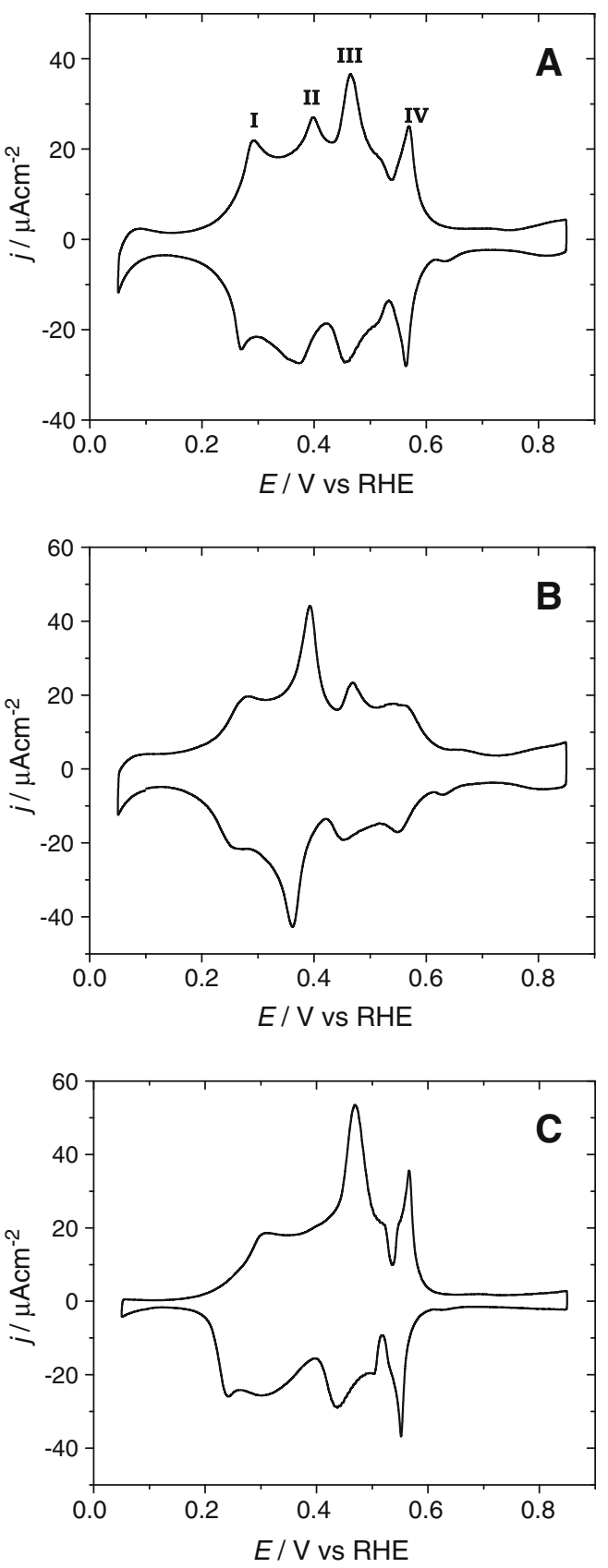

Fig. 1 Cyclic voltammogram of the same $\operatorname{Pt}(100)$ electrode pretreated by flame annealing and cooling in a $\mathrm{H}_{2} / \mathrm{Ar}$ (3:1) atmosphere, b $\mathrm{Ar}$ atmosphere and $\mathbf{c} \mathrm{CO} / \mathrm{Ar}(3: 1)$ atmosphere. The supporting electrolyte is $0.1 \mathrm{M} \mathrm{NaOH}$. Scan rate $=50 \mathrm{mV} / \mathrm{s}$

cooled down in $\mathrm{H}_{2} / \mathrm{Ar}$ and much higher than for the electrode cooled in Ar. In this regard, it is important to mention that the EC-STM images presented by Kibler et al. show that when the surface was cooled in $\mathrm{CO}$ atmosphere, the $\mathrm{CO}$ adsorption increases the mobility of the surface atoms, and after the lifting of the reconstruction of the Pt(100)-hex surface into $\operatorname{Pt}(100)-(1 \times 1)$, no monoatomic square islands were present on the surface [15]. Additionally, the STM images of the 


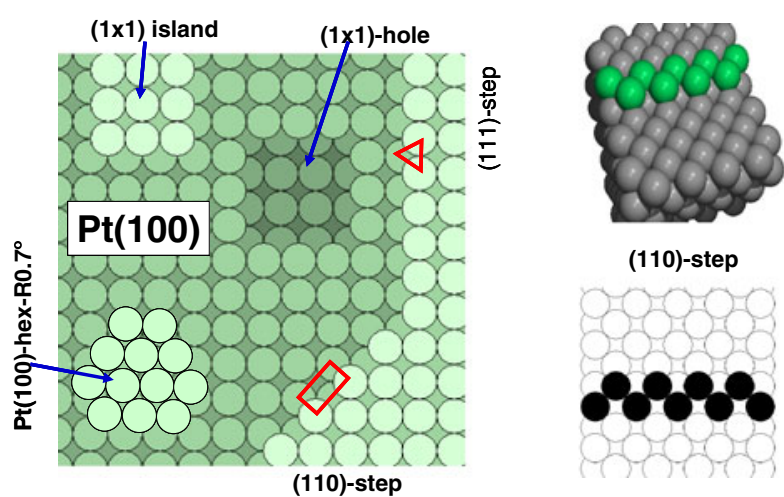

Fig. 2 Hard-sphere model of the $\mathrm{Pt}(100)$ with the different adsorption sites as a result of the different annealing treatments

$\operatorname{Pt}(100)$ annealed under these conditions do not show the presence of kink sites [15].

Summarising the analysis of the blank voltammetric profiles of the $\mathrm{Pt}(100)$ electrode under different surface treatment conditions, we assign peaks I and II to low coordinated adsorption sites (i.e. steps and defects) and the peaks III and IV to adsorption sites at terraces [17].

Next, we will discuss the influence of the cooling method on the oxidative stripping of $\mathrm{CO}$ adsorbed on the $\mathrm{Pt}(100)$. Figure 3 shows the CO stripping voltammetry of the $\operatorname{Pt}(100)$ electrodes obtained by the different annealing treatments. In the potential region between 0.1 and $0.5 \mathrm{~V}$, all the profiles are characterised by a complete blocking of hydrogen adsorption. At higher potential, the profiles exhibit marked differences. The surface cooled down in Ar (Fig. 3) presents a pre-wave presumably associated with the $\mathrm{CO}$ oxidation on low coordination sites and a main peak at higher potential $(0.64 \mathrm{~V})$. The pre-wave is absent in the other two voltammograms, in which the main peak appears at potentials higher than $0.69 \mathrm{~V}$. The voltammogram of the CO stripping at the surface cooled down in Ar presents only

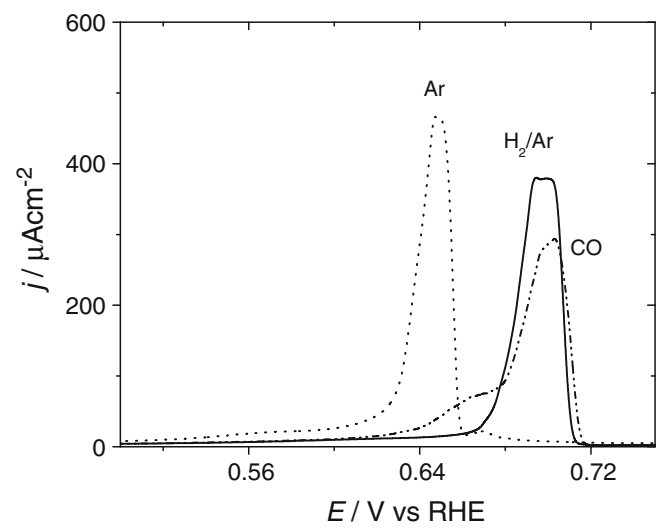

Fig. 3 CO stripping voltammogram of the $\mathrm{Pt}(100)$ electrode prepared by flame annealing and cooling in (solid line) $\mathrm{H}_{2} / \mathrm{Ar}$ (3:1) atmosphere (dashed line) $\mathrm{Ar}$ atmosphere and (dotted line) $\mathrm{CO} / \mathrm{Ar}$ (3:1) atmosphere. The supporting electrolyte is $0.1 \mathrm{M} \mathrm{NaOH}$. Scan rate $=20 \mathrm{mV} / \mathrm{s}$ a very small feature at $0.67 \mathrm{~V}$ that would correspond to a small amount of well-ordered terraces.

One of the more interesting observations is the difference in the $\mathrm{CO}$ oxidation profile between the surface treated in $\mathrm{H}_{2} / \mathrm{Ar}$ (Fig. 3) and the surface treated in $\mathrm{CO}$ atmosphere. The presence of a pre-wave is clearly observed between 0.62 and $0.69 \mathrm{~V}$ in the case of the surface cooled down in presence of $\mathrm{CO}$. One could assign the pre-wave to the oxidation of $\mathrm{CO}$ on the step edges of the square monoatomic island, as suggested by the potential at which it appears. However, as was described in [15], the surface cooled down in the presence of $\mathrm{CO}$ results in a flat surface free of square islands. The absence of these square islands was tentatively associated to the higher mobility of the atoms under these conditions leading to the formation of small islands. In such a case, the pre-wave in Fig. 3 (electrode cooled down in $\mathrm{CO}$ atmosphere) can be attributed to the oxidation of $\mathrm{CO}$ on the edges of this "nanoislands". Unfortunately, the ECSTM results in [15, 33] does not show a clear evidence of the presence of this nanoislands $[15,33]$.

Another tentative explanation of the pre-wave on the voltametric profile of the surface cooled down in $\mathrm{CO}$ is the presence of (110) step sites on the surface. One important observation has to be done with respect the EC-STM images reported in [15]. The step edges of the square monoatomic islands observed when the electrode was cooled down in the presence of $\mathrm{H}_{2} / \mathrm{Ar}$ are parallel and perpendicular to the $[0,-1$, -1] direction that corresponds to (111) step site. In contrast, the step edge on the surface cooled down in presence of $\mathrm{CO}$, in the same report show a large curvature, suggesting that the result is a combination of (111) and (110) sites. In this regard, one may suggest that the pre-wave observed in the $\mathrm{CO}$ stripping voltammogram of the surface cooled down in presence of $\mathrm{CO}$ could correspond to the $\mathrm{CO}$ oxidation on the (110) step sites (see Fig. 2), which could be more active than the (111) step sites present at the edges of the monoatomic islands. Although ECSTM images in [15] are just a local proof and those not reflect the behavior of the complete surface, the idea of the presence of (110) sites cannot a priori be discarded. Previous results of electrochemical oxidation of $\mathrm{CO}$ on platinum stepped surfaces $\mathrm{Pt}(\mathrm{S})-[n(100) \times(110)]$ in acidic media show that the most active site corresponds to the (110) step sites [24]. In contrast with the report of Hoshi et al. [24], the Alicante group recently presented a report in which it was shown that the $\mathrm{CO}$ oxidation activity on the $\operatorname{Pt}(n, 1,0)$ surface in acidic media decreases with increasing the step density [6]. In order to true assign the origin of the pre-wave and the reactive site, more detailed ECSTM studies are required.

In previous reports, the low potential oxidation peak on the $\operatorname{Pt}(111)$ in alkaline media was associated with the presence of kink sites [8]. Based on experimental data of 
voltammograms at low scan rates and chronoamperometries of the CO oxidation on $\mathrm{Pt}(111)$ and step surfaces in alkaline media $[9,10]$ and $\operatorname{Pt}(100)$ in acidic media [25], the authors suggest that the oxidation of $\mathrm{CO}$ follow a nucleation and grow behavior. The instantaneous nucleation of $\mathrm{OH}$ (responsible of the oxidation) takes place on the steps sites. The presence of large amount of defects on the surface when the electrode is cooled down in Ar atmosphere should be the responsible of the early oxidation of CO. Tentative and based on previous observation, we can suggest that the (110) step sites or small islands present on the surface cooled down in the presence of $\mathrm{CO}$ acts as nucleation centers of $\mathrm{OH}$ adsorption, and it is easier than on the (111) step edges at the monoatomic islands present on the $\mathrm{Pt}(100)$ cooled down in $\mathrm{H}_{2} / \mathrm{Ar}$.

In relation to the charge associated with the $\mathrm{CO}$ oxidation, the surface cooled down in the presence of $\mathrm{CO}$ gives a charge of $520 \pm 12 \mu \mathrm{C} \mathrm{cm}^{-2}$ (uncorrected by anion adsorption), which is around $10 \%$ smaller in comparison with the surface cooled down in $\operatorname{Ar}\left(560 \pm 25 \mu \mathrm{C} \mathrm{cm}^{-2}\right.$ uncorrected by the anion adsorption). On the other hand, it is $10 \%$ higher that the value obtained for the surface cooled down in the presence of $\mathrm{H}_{2} / \mathrm{Ar}\left(480 \pm 18 \mu \mathrm{C} \mathrm{\textrm {cm } ^ { - 2 }}\right.$ uncorrected by the anion adsorption). The difference in the charge may be partially associated to the excess of platinum atoms on the surface as a result of the adsorption of oxygen traces of during the cooling treatment ( $\mathrm{Ar}$ atmosphere) and is smaller for a well-ordered surface ( $\mathrm{CO} / \mathrm{Ar}$ atmosphere). However, the different charges mentioned above can also be associated to different coverage of the CO layer on a fully blocked surface. It is well documented in the literature $[26,27]$ that a fully CO blocked $\mathrm{Pt}(111)$ surface in acidic media presents two different adlayer domains: $(2 \times 2)-3 \mathrm{CO}(\theta=0.75)$ and $(\sqrt{19} \times \sqrt{19}) \mathrm{R} 23.3^{\circ}-13 \mathrm{CO}(\theta=0.68)$. It is important to mention that the compressive forces required to create the $(2 \times 2)-3 \mathrm{CO}$ adlayer characteristic of the $\mathrm{Pt}(111) / \mathrm{CO}$ was only achieved with a substantial long-range substrate order. Such condensed CO adlayers have also been observed on $\operatorname{Pt}(100)$ in acidic media by Wakisaka et al. [28], having a coverage of ca. 0.75 . One way to discriminate between the two possibilities, surface atoms excess or differences in the coverage, is by looking at charge of the hydrogen adsorption region in Fig. 1. The $\mathrm{Pt}(100)$ cooled down in Ar atmosphere presents a charge of $280 \mu \mathrm{C} \mathrm{cm}^{-2}$, which is $5 \%$ and $10 \%$ larger than the charge associated to the hydrogen adsorption region on the $\mathrm{Pt}(100)$ cooled down on $\mathrm{H}_{2} / \mathrm{Ar}$ and $\mathrm{CO} / \mathrm{Ar}$ atmosphere respectively. The fact that the surface cooled down in Ar presents the larger charge of $\mathrm{H}_{2}$ adsorption and $\mathrm{CO}$ oxidation reflect a higher roughness of the surface. On the other hand, the $\mathrm{Pt}(100)$ cooled down in $\mathrm{CO} / \mathrm{Ar}$ atmosphere shows the least hydrogen adsorption charge but larger $\mathrm{CO}$ oxidation charge compared to the surface annealed under $\mathrm{H}_{2} / \mathrm{Ar}$ atmosphere. This suggests the presence of a well-order structure and a more compact adlayer of $\mathrm{CO}$ with higher coverage. An alternative way to look in the different coverage is by following the potential dependence infrared spectra of the $\mathrm{CO}$ oxidation. As the compressed adlayers exhibit different adsorption geometries, the electrochemical oxidation of adsorbed $\mathrm{CO}$ on the $\operatorname{Pt}(100)$ after different annealing procedures was also followed by FTIR in order to determine the preferential site of $\mathrm{CO}$ adsorption in each case. Figures 4 and 5 show the different spectra and the integrals of the CO bands on the $\mathrm{Pt}(100)$, as a function of potential, for the three different annealing treatments, respectively.

Figure 4 shows the potential dependence of the FTIR spectra of adsorbed $\mathrm{CO}$ on $\mathrm{Pt}(100)$ in $0.1 \mathrm{M} \mathrm{NaOH}$. The
Fig. 4 FTIR spectra for the oxidation of $\mathrm{CO}$ adsorbed on $\mathrm{Pt}(100)$ in $0.1 \mathrm{M} \mathrm{NaOH}$ for the electrode annealed in $\mathrm{a}_{2} / \mathrm{Ar}$ (3:1) atmosphere, $\mathbf{b} \mathrm{Ar}$ atmosphere and $\mathbf{c} \mathrm{CO} / \mathrm{Ar}(3: 1)$ atmosphere. The potential was stepped from $0.05 \mathrm{~V}$ in $0.05 \mathrm{~V}$ steps up to $0.8 \mathrm{~V}$. Adsorption potential $E_{\text {ad }}=0.05 \mathrm{~V}$ vs RHE and reference potential is $E_{\text {ref }}=0.8 \mathrm{~V}$ vs RHE. The sample potentials corresponding to each spectrum are indicated in the figure
A

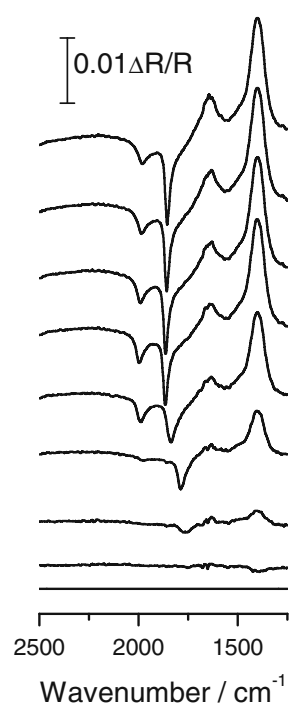

B

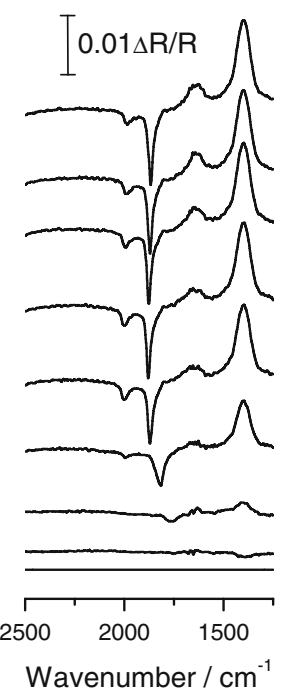

C

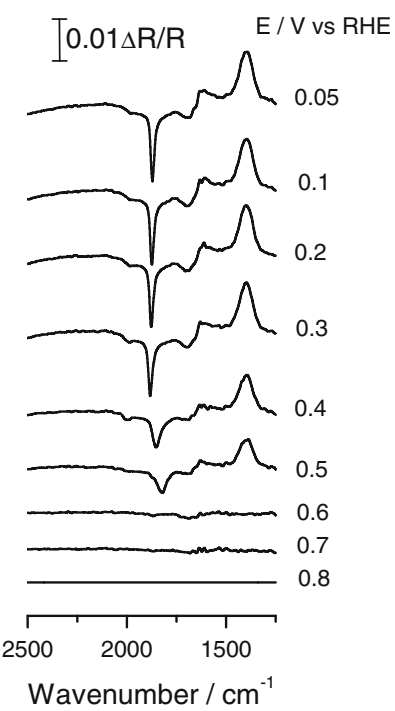



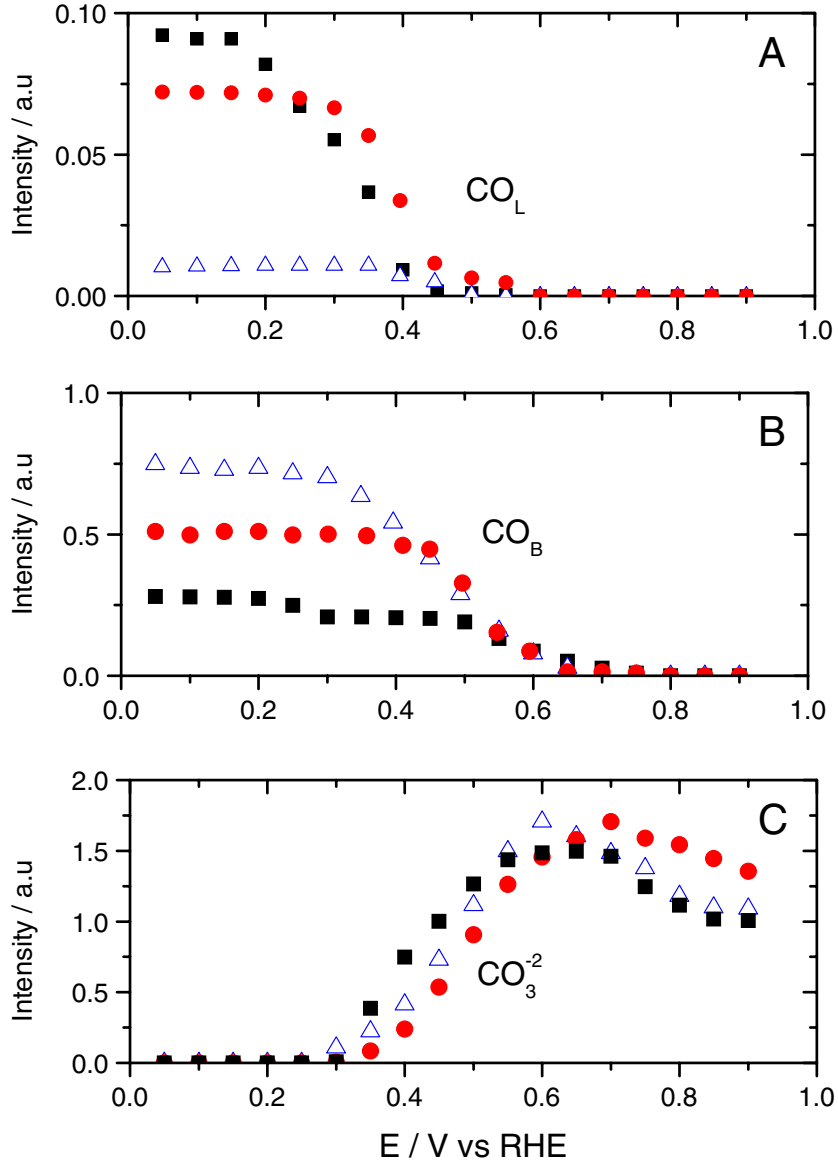

Fig. 5 Potential dependence of the integrated band intensities for $\mathrm{CO}_{\mathrm{L}}$ (upper panel), $\mathrm{CO}_{\mathrm{B}}$ (middle panel) and carbonate (bottom panel). $\mathrm{Pt}$ (100) electrode in $0.1 \mathrm{M} \mathrm{NaOH}$, annealed in $\mathrm{H}_{2} / \mathrm{Ar}$ (3:1) atmosphere $(\bullet), \operatorname{Ar}(\bullet)$ and $\mathrm{CO} / \mathrm{Ar}(3: 1)$ atmosphere $(\Delta)$. The integral values were obtained from the spectra of Fig. 4 using $0.8 \mathrm{~V}$ as reference spectra

rate at which these spectra were taken corresponds to an effective scan rate of $10 \mathrm{mV} / \mathrm{s}$. As a general characteristic in the spectra, two negative bands that diminish in intensity are observed. These two bands are associated to the stretching mode of $\mathrm{CO}$ adsorbed on top $\left(\mathrm{CO}_{\mathrm{L}}\right)$ and bridge sites $\left(\mathrm{CO}_{\mathrm{B}}\right)$. From Fig. 4 , it can be also observed that at more positive potentials, these features are accompanied by the appearance of (initially) weak positive bands at about 1,650 and $1,400 \mathrm{~cm}^{-1}$. The first band is described in the literature as the $\mathrm{O}-\mathrm{H}$ bending mode of water and is related to the instability of the thin layer [29], while the band at $1,400 \mathrm{~cm}^{-1}$ can be associated to the formation of a carbonaceous species $[30,31]$. Table 1 summarises the peak positions of the $\mathrm{CO}_{\mathrm{L}}$ and $\mathrm{CO}_{\mathrm{B}}$ for the three annealing procedures. For the sake of comparison, the values corresponding to the $\mathrm{CO}$ adsorption in acidic media are included in parentheses.

The values corresponding to the frequencies of the $\mathrm{CO}$ adsorbed on the $\operatorname{Pt}(100)$ as presented in Table 1 are in
Table 1 FTIR wavenumber values for $\mathrm{CO}$ adsorbed at $0.05 \mathrm{~V}$ on $\mathrm{Pt}$ $(100)$ as a function of the annealing procedure $\left(E_{\text {sample }}, 0.8 \mathrm{~V}\right)$

\begin{tabular}{lll}
\hline $\begin{array}{l}\text { Annealing } \\
\text { treatment }\end{array}$ & $\begin{array}{l}\text { Wavenumber } \\
\mathrm{CO}_{\mathrm{L}}\left(\mathrm{cm}^{-1}\right)\end{array}$ & $\begin{array}{l}\text { Wavenumber } \\
\mathrm{CO}_{\mathrm{B}}\left(\mathrm{cm}^{-1}\right)\end{array}$ \\
\hline $\mathrm{H}_{2} / \mathrm{Ar}$ & $1,987\left(2,053^{\mathrm{a}} ; 2,032^{\mathrm{b}}\right)$ & $1,865\left(1,855^{\mathrm{a}} ; 1,866^{\mathrm{b}}\right)$ \\
$\mathrm{Ar}$ & 1,992 & 1,860 \\
$\mathrm{CO} / \mathrm{Ar}$ & 1,966 & 1,872 \\
\hline
\end{tabular}

${ }^{\mathrm{a}}$ Wavenumber values for the $\mathrm{CO}$ adsorbed on $\mathrm{Pt}(100)$ at $0.05 \mathrm{~V}$ in $0.1 \mathrm{M} \mathrm{H}_{2} \mathrm{SO}_{4}$ from [36]

${ }^{\mathrm{b}}$ Wavenumber values for the $\mathrm{CO}$ adsorbed $\left(\theta_{\mathrm{CO}}=0.6\right)$ on $\mathrm{Pt}(100)$ at $0.05 \mathrm{~V}$ in $0.1 \mathrm{M} \mathrm{HClO}_{4}$ from [33]

agreement with the values reported in the literature based on experimental and DFT methods [32, 33]. However, in comparison with previous results in acidic media, the $\mathrm{CO}$ adsorbed on bridge site (about $1,865 \mathrm{~cm}^{-1}$ ) presents the major contribution in the spectra independently of the atmosphere used for cooling down the surface. As can be seen in Fig. 4 and most clearly in the values of the integrals in Fig. 5, the $\mathrm{CO}_{\mathrm{L}}$ stretching band is almost negligible in comparison to the $\mathrm{CO}_{\mathrm{B}}$ feature when the electrode was cooled down in a $\mathrm{CO} / \mathrm{Ar}$ atmosphere. In comparison with the other two cooling treatments, the band of the $\mathrm{CO}_{\mathrm{L}}$ is most significant when the electrode was cooled down in $\mathrm{Ar}$ atmosphere. In contrast with our results, in acidic media, Lopez-Cudero et al. obtained a very different contribution from the $\mathrm{CO}_{\mathrm{L}}$ and $\mathrm{CO}_{\mathrm{B}}$ adsorbed on the $\operatorname{Pt}(100)$ surface, the major contribution being the band at around 2,056 $\mathrm{cm}^{-1}$ assigned to the $\mathrm{CO}_{\mathrm{L}}$ and a smaller band at about $1,820 \mathrm{~cm}^{-1}$ [34]. As for the latter band, based on the irreproducibility and also on the non-linear dependence of these bands with the potential, the authors suggest that it is related to the topography of the surface and the coverage of the $\mathrm{CO}$, the band being more intense at lower coverage of $\mathrm{CO}$. However, for higher coverages (maximum coverage of 0.79 ) or in the presence of $\mathrm{CO}$ in solution, the band related to $\mathrm{CO}_{\mathrm{B}}$ becomes larger as is reported $[34,35]$.

The difference in the behavior of $\mathrm{CO}$ adsorption on $\operatorname{Pt}(100)$ between acidic and alkaline media may be addressed mainly to two factors. First, the higher $\mathrm{CO}_{\mathrm{B}}$ abundance observed in alkaline media has to be related to an electronic effect. The "real" electrode potential is more negative in alkaline media (or the effective Fermi level more positive), with respect to the $\mathrm{pH}$-independent levels in solution (i.e., the NHE scale), and consequently, an enhanced effect of back-donation into the Pt-CO bond is expected [36]. DFT calculations have shown that the latter effect may produce a stronger bonding interaction between $\mathrm{Pt}$ and $\mathrm{CO}$ and that multifold coordination is favored at these negative electrochemical potentials [37, 38]. Second, the introduction of a small amount of defects 
dramatically changes the $\mathrm{CO}$ adsorption state, while defect density increases the $\mathrm{CO}_{\mathrm{B}}$ decreases (or which is the same the $\mathrm{CO}_{\mathrm{L}}$ increases). Apparently, a long-range order of the (100) terrace is necessary to detect only $\mathrm{CO}_{\mathrm{B}}$. Additionally, a red shift of the $\mathrm{CO}_{\mathrm{L}}$ and $\mathrm{CO}_{\mathrm{B}}$ band centers is observed, compared to the experiment carried out with the $\operatorname{Pt}(100)$ surface annealed in $\mathrm{CO} / \mathrm{Ar}$. Again, this band center shift may be attributed to the higher amount of defects on these surfaces [18]. These latter observations emphasise the importance of long-range order to obtain a compressed CO adlayer and confirm the previous observation obtained by analysis of the charges, that is, on the $\mathrm{CO} / \mathrm{Ar}$ annealed surfaces, the CO coverage is larger due to the large order surface structure and the absence of islands.

In Fig. 5, it can be also seen how the signals related to the $\mathrm{CO}_{\mathrm{L}}$ decrease at more negative potentials than the corresponding one of the $\mathrm{CO}_{\mathrm{B}}$ for all the different flame annealed treatments. Moreover, from the same figure is observable that $\mathrm{CO}$ adsorbed in bridge configuration is the most strongly adsorbed CO (i.e. the least reactive) and is completely removed from the Pt surface at potentials higher than $0.65 \mathrm{~V}$. The latter was observed during the $\mathrm{CO}$ oxidation on slightly disordered $\mathrm{Pt}(111)$ electrode in alkaline media [18], in which it was associated to CO adsorbed in a bridge site on the top of the step site. Therefore, this $\mathrm{CO}_{\mathrm{b}}$ is oxidised by $\mathrm{OH}$ adsorbed on the $\mathrm{Pt}$ (100) terrace at very positive potentials. It should be noted that the last affirmation is in perfect agreement with the anodic currents observed during the CO stripping voltammograms (Fig. 3).

It is also clearly seen in Fig. 5 that the formation of carbonate starts slightly earlier in the case of the electrode cooled down in Ar. It is also important to note that, when the electrodes are cooled down in $\mathrm{H}_{2} / \mathrm{Ar}$ or $\mathrm{CO} / \mathrm{Ar}$, the $\mathrm{CO}$ and carbonate bands disappear/appear respectively in a very similar way and at similar potentials. The oxidation on the surface cooled down in $\mathrm{CO} / \mathrm{Ar}$ starts slightly earlier respect to the annealed with $\mathrm{H}_{2} / \mathrm{Ar}$, as was also observed in the voltammogram of Fig. 1. The low-potential oxidation of $\mathrm{CO}$ on this surface could be associated with the oxidation of $\mathrm{CO}$ at the (110) step sites as was mentioned before. However, it can be also attributed to the oxidation of the metastable compressed adlayer.

\section{$\operatorname{Pt}(110)$}

Figure $6 \mathrm{a}$ and $\mathrm{b}$ shows the cyclic voltammograms of the $\mathrm{Pt}(110)$ electrode in $0.1 \mathrm{M} \mathrm{NaOH}$ recorded after cooling the electrode in a $\mathrm{H}_{2} / \mathrm{Ar}$ atmosphere and air, respectively. Additionally, the voltametric profile of the $\operatorname{Pt}(110)$ cooled down in $I_{2}$ vapor (see "Experimental") is shown in the Fig. 6c. As can be seen in the figure, the profiles present a very similar behavior below $0.3 \mathrm{~V}$ vs RHE, although some
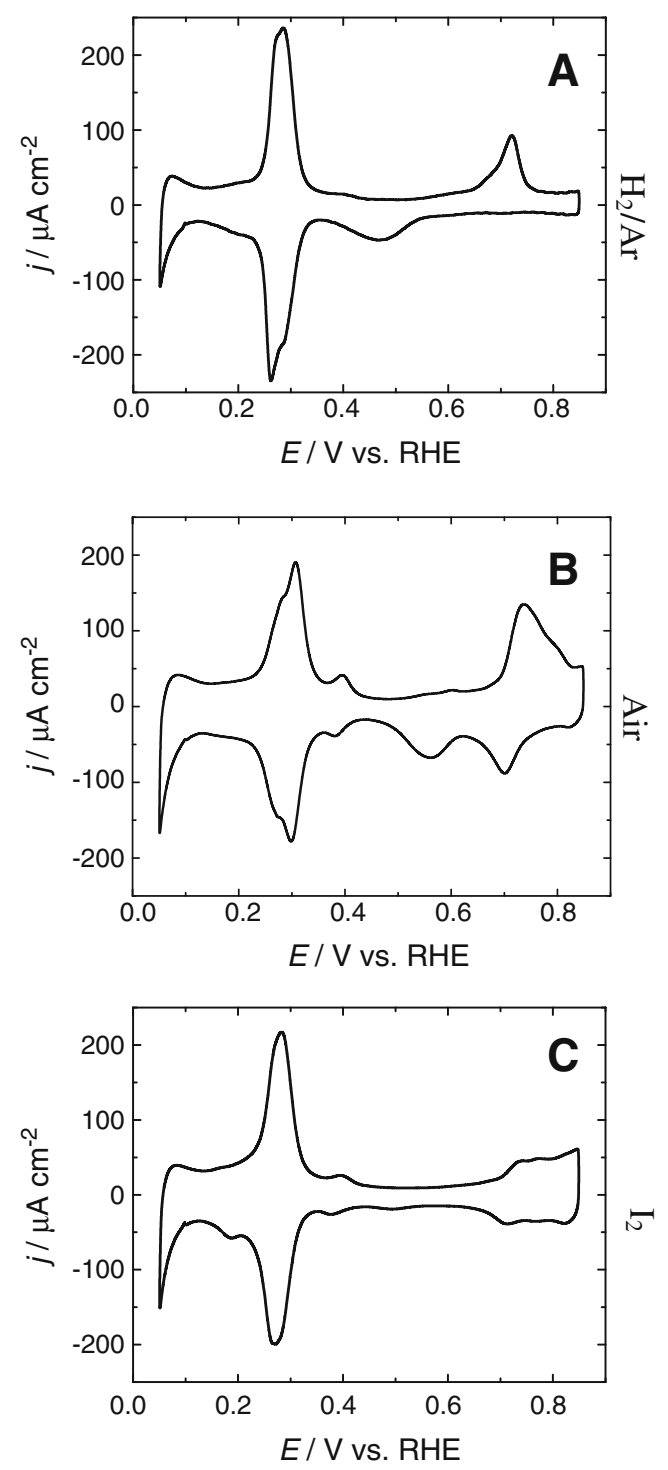

Fig. 6 Cyclic voltammogram of the same $\mathrm{Pt}(110)$ electrode pretreated by flame annealing and cooling in $\mathbf{a} \mathrm{H}_{2} / \mathrm{Ar}(3: 1)$ atmosphere, b air atmosphere and $\mathbf{c} \mathrm{I}_{2}$ vapor. The supporting electrolyte is $0.1 \mathrm{M} \mathrm{NaOH}$. Scan rate $=50 \mathrm{mV} / \mathrm{s}$

differences can be observed for each treatment. In the case of the electrodes annealed and subsequently cooled down in Air and $\mathrm{H}_{2} / \mathrm{Ar}$, the main peak seems to present two separate current contributions at 0.28 and $0.30 \mathrm{~V}$. The more negative contribution is significantly higher in the surface cooled down in presence of $\mathrm{H}_{2}$ and shifted slightly to more negative potential $(0.26 \mathrm{~V})$, and the contribution at $0.3 \mathrm{~V}$ is more important when the electrode was cooled down in absence of $\mathrm{H}_{2}$. On the other hand, if the electrode is cooled down in presence of $\mathrm{I}_{2}$ vapor, the voltammetric profile presents an apparently single peak at $0.28 \mathrm{~V}$ where the two contributions cannot be distinguished. However, at potentials higher than $0.3 \mathrm{~V}$, remarkable differences can be observed between the profiles of the different surfaces. These differences can be 
ascribed to the different adsorption sites present on the surface. The peak at $0.39 \mathrm{~V}$ (reversible) and at $0.73 \mathrm{~V}$ in the anodic scan $(0.69 \mathrm{~V}$ in the cathodic scan) present in the profiles of the surfaces cooled down in air and $\mathrm{I}_{2}$ vapor could be ascribed to the presence of defects on the surface [8]. Similar features are observed when the well-ordered and freshly annealed electrode is cycled up to oxidation potentials [39]. It has been also reported that the surface contains a non-negligible number of defects even after hydrogen cooling [40]. Regarding the surface structure, previous studies by ex situ low-energy electron diffraction [41-43] have shown that the $(1 \times 2) \operatorname{Pt}(110)$ surface is stable in perchloric and sulfuric acid solution if the potential is restricted to potentials below $0.7 \mathrm{~V}$. There is no previous report based on in situ techniques that shows the presence of the $(1 \times 2)$ reconstruction of the $\operatorname{Pt}(110)$ in an electrochemical environment. If there were a fast potential-induced reconstruction, the conclusions about the stability range for $\operatorname{Pt}(110)$ could be wrong (like for $\mathrm{Au}(110)$ [43]) because the $(1 \times 2)$ structure could be formed back from $(1 \times 1)$ at the immersion potential. However, Pt atoms have a much lower surface mobility than Au atoms, and hence, a potential-induced surface reconstruction should be kinetically strongly hindered.

Since the surface structure of the $\operatorname{Pt}(110)$ is strongly affected by the annealing treatment, it is expected that significant changes in the $\mathrm{CO}$ oxidation stripping curves and also in the adsorption sites of the $\mathrm{CO}$ will be observed. In order to confirm this expectation, stripping voltammetry and FTIR experiments were performed.

Figure 7 shows the potential sweeps in $0.1 \mathrm{M} \mathrm{NaOH}$ at $20 \mathrm{mV} \mathrm{s}^{-1}$ for the anodic stripping of $\mathrm{CO}$ adsorbed on the $\mathrm{Pt}(110)$ treated in the previously described atmospheres. As in the case of $\operatorname{Pt}(100)$, the complete blockage of the surfaces was confirmed by the absence of current density in the region between 0.1 and $0.3 \mathrm{~V}$ associated to the adsorption/desorption of hydrogen. Significant differences were found as a function of the annealing treatment. In the case of the electrode quenched with water (i.e. fast cooling down in air), the voltametric profile of the Fig. $7 \mathrm{~b}$ presents a "pre-wave" (0.3-0.5 V) that was found previously for the $\mathrm{Pt}(111)$ surface, and it could be ascribed to oxidation of $\mathrm{CO}$ at defect sites, more specifically kink sites [8, 18]. Increasing the electrode potential from 0.5 to $0.7 \mathrm{~V}$, two overlapping contributions in the $\mathrm{CO}$ oxidation can be observed, and those might be associated to the oxidation of $\mathrm{CO}$ on terrace sites. The broadness of these voltammetric features should be associated to a large distribution of terraces sites, with peak potentials suggesting relatively short terraces with $(1 \times 1)-\operatorname{Pt}(110)$ structure. Additionally, a small contribution in current is observed at higher potentials. As we reported for the oxidation of $\mathrm{CO}$ on $\mathrm{Pt}(111)$ in alkaline media $[8-10,18]$, the late oxidation of $\mathrm{CO}$ may be attributed
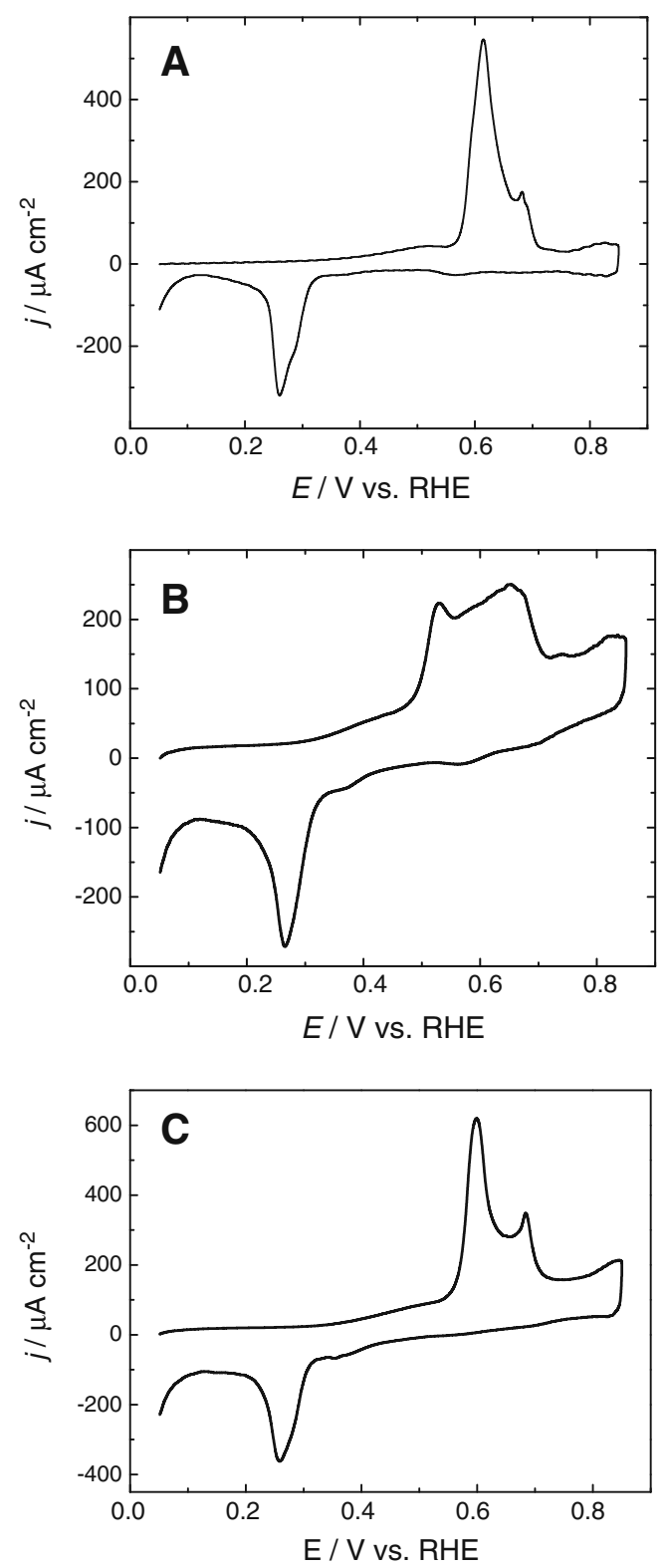

Fig. 7 CO stripping voltammogram of the $\mathrm{Pt}(110)$ electrode prepared by flame annealing and cooling in $\mathbf{a} \mathrm{H}_{2} / \mathrm{Ar}(3: 1)$ atmosphere, b air and $\mathbf{c} \mathrm{I}_{2}$ vapor. The supporting electrolyte is $0.1 \mathrm{M} \mathrm{NaOH}$. Scan rate $=20 \mathrm{mV} / \mathrm{s}$

to the $\mathrm{CO}$ adsorbed on the step site oxidised by $\mathrm{OH}$ adsorbed on terrace site. The broad potential window for $\mathrm{CO}$ oxidation likely corresponds to the contribution of terraces with different width.

When the electrode was flame annealed and cooled down in a $\mathrm{H}_{2} /$ Ar saturated atmosphere, the voltammogram (shown in Fig. 7a) shows two well-defined potential regions: a small pre-peak between 0.4 and $0.6 \mathrm{~V}$, as in Fig. $7 \mathrm{~b}$ but now with lower current density, and a main peak at $0.6 \mathrm{~V}$. As was mentioned before the peak at $0.6 \mathrm{~V}$ can be associated to the oxidation of $\mathrm{CO}$ at the terrace sites with $(1 \times 1)-\operatorname{Pt}(110)$ structure. Analysing the voltammogram more in detail, the peak at $0.6 \mathrm{~V}$ presents a small shoulder 
at $0.68 \mathrm{~V}$ that may be associated to a site with lower reactivity towards the $\mathrm{CO}$ oxidation, i.e. the produced surface has principal domains (terraces) and a low defect density (steps and kinks). Moreover, these defects seem to be more of long range (step) than short range (kink). The last assumption is supported by previous studies [8-10], in which the step site has two different catalytic activities towards the $\mathrm{CO}$ oxidation: $\mathrm{CO}$ adsorbed below the step is more reactive than the $\mathrm{CO}$ adsorbed further away on the terrace (pre-peak at about $0.5 \mathrm{~V}$ ), while $\mathrm{CO}$ adsorbed at the step is the least active. The curves of the CO stripping experiments confirm the observations that flame annealing in $\mathrm{H}_{2} / \mathrm{Ar}$ leads to a surface with homogeneous and larger well-ordered terraces in comparison with the surface cooled down in absence of $\mathrm{H}_{2}$.

The most significant results were obtained when the electrode was cooled down in $\mathrm{I}_{2}$. The voltammogram looks similar to the profile of the electrode cooled down in $\mathrm{H}_{2} / \mathrm{Ar}$, but the ratio of the peaks at 0.6 and $0.68 \mathrm{~V}$ is quite different; in this case, the peak developed at more positive potentials is well resolved and has a higher charge. As was mentioned before and similar to the behavior of the $\mathrm{CO}$ oxidation on $\mathrm{Pt}(111)$ [8-10], the feature at $0.68 \mathrm{~V}$ (late $\mathrm{CO}$ oxidation) may correspond to the $\mathrm{CO}$ strongly adsorbed on the step site oxidised by $\mathrm{OH}$ adsorbed on terrace site. $\mathrm{CO}$ adsorbed on such a low coordinated site should present significant difference in adsorption energy as well as in vibrational frequency with respect to the $\mathrm{CO}$ adsorbed on other platinum sites [36].

Figures 8 and 9 show the difference spectra and the integrals of the bands corresponding to $\mathrm{CO}$ oxidation on the $\operatorname{Pt}(110)$ after the three different annealing treatments. Table 2 summarises the peak positions corresponding to the observed CO frequencies. In general, Fig. 9 shows some very important differences with respect the spectrum of $\mathrm{CO}$ on Pt(110) in UHV and acidic media. In UHV and acidic media, CO adsorption on $\operatorname{Pt}(110)$ shows a single band located at around 2,150 and 2,050 $\mathrm{cm}^{-1}$, respectively, for a similar coverage of 0.5 [44]. By contrast, in alkaline media, Fig. 9 shows the coexistence of two or even three different adsorption sites of $\mathrm{CO}$ for the same maximum coverage of 0.5 . The band corresponding to the linearly bonded $\mathrm{CO}$ $\left(\mathrm{CO}_{\mathrm{L}}\right)$ appears at lower wavenumbers (about 2,030 $\mathrm{cm}^{-1}$ ) than in acidic media, and the band position depends sensitively on the cooling treatment. Density Functional Theory (DFT) calculations have shown that the effect of the more negative potential, or the effectively higher Fermi level, may produce a stronger bonding interaction between Pt and CO [37, 38, 45]. It will typically also lead to lower $\mathrm{CO}$ stretching frequencies and to an enhanced propensity to multifold coordination. A second small vibration band related to bridge $\mathrm{CO}\left(\mathrm{CO}_{\mathrm{B}}\right)$ appears at around $1,847 \mathrm{~cm}^{-1}$, but it does not depend on the employed cooling treatment. In addition to these two bands, the spectra recorded during the $\mathrm{CO}$ oxidation on the $\mathrm{Pt}(110)$ cooled down in $\mathrm{I}_{2}$ vapor exhibit a band not reported previously at $1,955 \mathrm{~cm}^{-1}\left(\mathrm{CO}_{\mathrm{L}}^{*}\right)$. As can be observed in the spectra of Fig. 8c, this negative band is present in the potential region between the initial potential and starts to decrease at higher potentials than $0.3 \mathrm{~V}$. This band at $1,955 \mathrm{~cm}^{-1}$ appears close to a band at $1,920 \mathrm{~cm}^{-1}$ observed by Ito et al. on stepped $\operatorname{Pt}(2 n-1,1,1)$ electrodes with (100) terraces and (111) step sites in acidic media [46]. In UHV environment, Bare et al. reported the formation of an intermediate state of $\mathrm{CO}$ adsorbed on a "short bridge state" at $1,915 \mathrm{~cm}^{-1}$, in the coverage range $0.5<\theta<0.9$ after partial desorption of the $\mathrm{CO}$ using high
Fig. 8 FTIR spectra for the oxidation of $\mathrm{CO}$ adsorbed on $\mathrm{Pt}(110)$ in $0.1 \mathrm{M} \mathrm{NaOH}$ for an electrode annealed in $\mathbf{a ~} \mathrm{H}_{2} / \mathrm{Ar}$ (3:1) atmosphere, b air and $\mathbf{c} \mathrm{I}_{2}$ vapors. The potential was stepped from $0.05 \mathrm{~V}$ in $0.05 \mathrm{~V}$ steps up to $0.8 \mathrm{~V}$. Adsorption potential $E_{\mathrm{ad}}=0.05 \mathrm{~V}$ vs RHE and reference potential is $E_{\text {ref }}=0.8 \mathrm{~V}$ vs RHE. The sample potentials corresponding to each spectrum are indicated in the figure
A

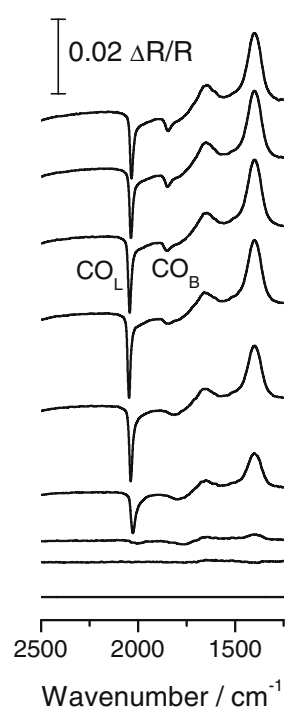

B

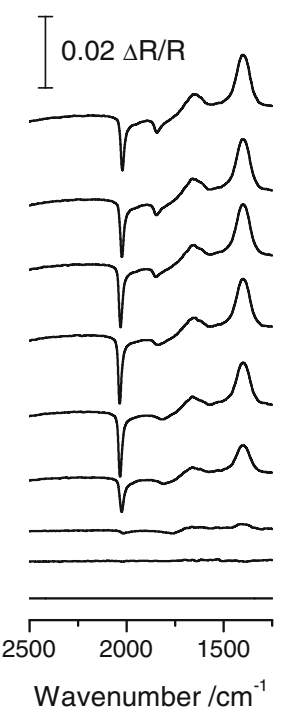

C

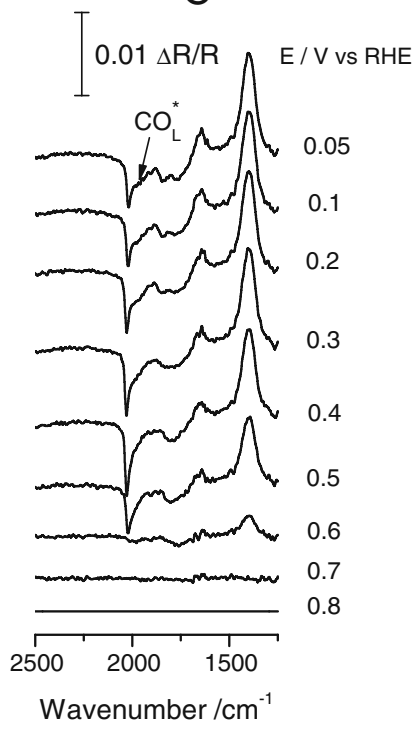



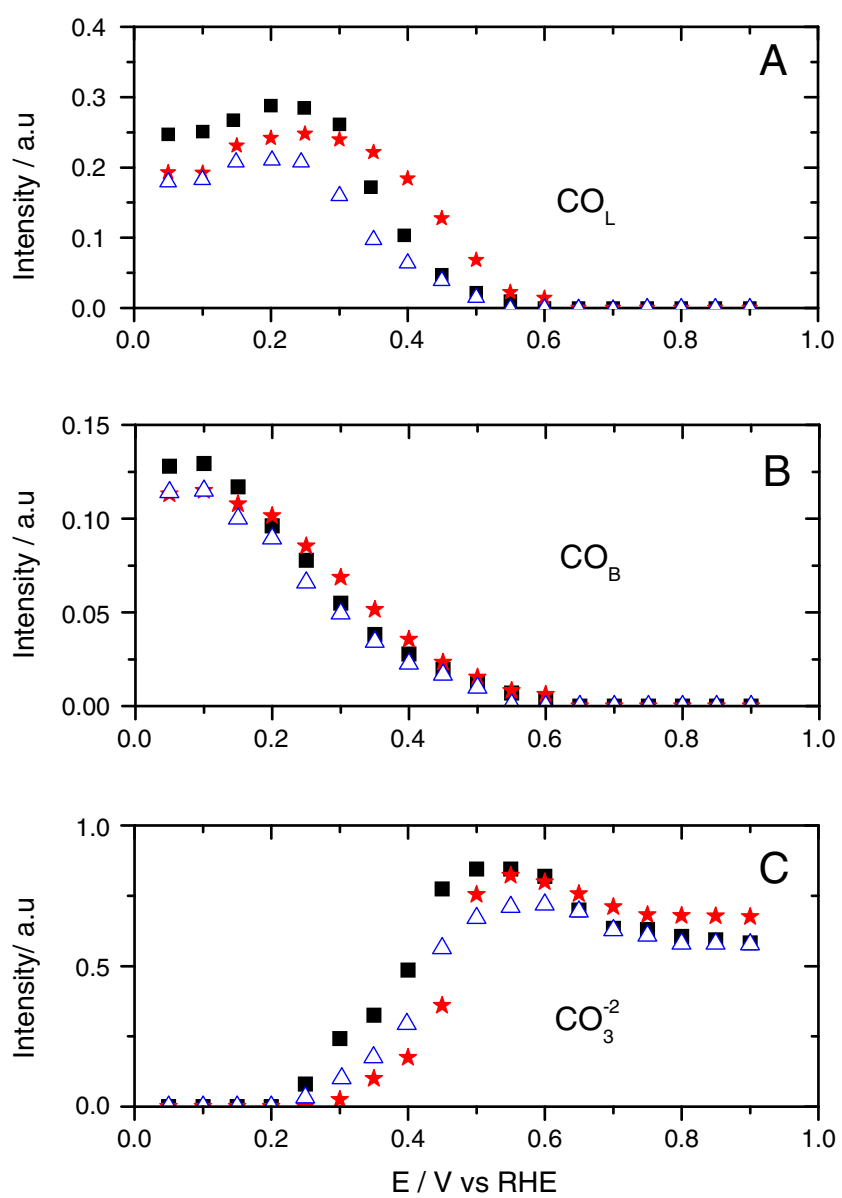

Fig. 9 Potential dependence of the integrated band intensities for $\mathrm{CO}_{\mathrm{L}}$ (upper panel), $\mathrm{CO}_{\mathrm{B}}$ (middle panel) and carbonate (bottom panel). $\mathrm{Pt}(110)$ electrode in $0.1 \mathrm{M} \mathrm{NaOH}$, annealed in $\mathrm{H}_{2} / \mathrm{Ar}(3: 1)$ atmosphere $(\star)$, air (ロ) and $\mathrm{I}_{2}$ vapor $(\Delta)$. The integral values were obtained from the spectra of Fig. 9 using 0.8 V as reference spectra

resolution electron energy loss spectroscopy [47]. In addition to these experimental values observed in UHV, Yamagishi et al. [32] proposed the presence of a $\mathrm{CO}$ linearly bonded on the $(1 \times 2)-\operatorname{Pt}(110)$ with a tilt angle with respect to the (110) normal with a stretching frequency of $1,922 \mathrm{~cm}^{-1}$ on the basis of DFT calculations, which is close to the value obtained in this work. Unfortunately, the fact

Table 2 FTIR wavenumber values for $\mathrm{CO}$ adsorbed at $0.05 \mathrm{~V}$ on $\mathrm{Pt}$ $(110)$ as a function of the annealing procedure $\left(E_{\text {sample }}, 0.8 \mathrm{~V}\right)$

\begin{tabular}{lll}
\hline $\begin{array}{l}\text { Annealing } \\
\text { treatment }\end{array}$ & $\begin{array}{l}\text { Wavenumber } \\
\mathrm{CO}_{\mathrm{L}}\left(\mathrm{cm}^{-1}\right)\end{array}$ & $\begin{array}{l}\text { Wavenumber } \\
\mathrm{CO}_{\mathrm{B}}\left(\mathrm{cm}^{-1}\right)\end{array}$ \\
\hline $\mathrm{H}_{2} / \mathrm{Ar}$ & $2,040\left(2,050^{\mathrm{a}}\right)$ & 1,849 \\
$\mathrm{Air}$ & 2,019 & 1,847 \\
$\mathrm{I}_{2}$ & 2,025 and $1,955^{*}$ & 1,847
\end{tabular}

${ }^{\mathrm{a}}$ Wavenumber values for the $\mathrm{CO}$ adsorbed on $\mathrm{Pt}(110)$ at $-0.1 \mathrm{~V}$ vs SCE $(\theta=0.5)$ in $0.1 \mathrm{M} \mathrm{HClO}_{4}$ from [44]

* corresponds to the band denoted as $\mathrm{CO}_{\mathrm{L}}$ that the band overlaps with the other $\mathrm{CO}_{\mathrm{L}}$ band at $2,025 \mathrm{~cm}^{-1}$, irrespective of which reference potential is taken $\left(E_{\text {ref }}=0.05 \mathrm{~V}, E_{\text {ref }}=0.9\right.$ Vor $\left.E_{\text {ref }}=0.4 \mathrm{~V}\right)$, complicates the accurate integration and the estimation of the Stark tuning shift of the bands. The lower frequency observed for the $\mathrm{CO}_{\mathrm{L}}^{*}$ may be explained by an increase in the back donation produced by atoms with lower coordination (i.e. steps). Moreover, it is observed that the band intensity related to $\mathrm{CO}_{\mathrm{L}}^{*}$ decreases at potentials higher than $0.3 \mathrm{~V}$, which is about $0.15 \mathrm{~V}$ more positive than the observed for $\mathrm{CO}_{\mathrm{B}}$. Consequently, it is possible to suggest a picture of the system at the initial potential $(0.05 \mathrm{~V})$, with linear $\mathrm{CO}$ adsorbed at two different sites, i.e. $\mathrm{CO}_{\mathrm{L}}$ adsorbed on terraces with $(1 \times 2)-\operatorname{Pt}(110)$ and $\mathrm{CO}_{\mathrm{L}}^{*}$ adsorbed on the missing row step. Next, as potential increases, the $\mathrm{CO}_{\mathrm{B}}$ oxidises at $E>0.15 \mathrm{~V}$, while the $\mathrm{CO}_{\mathrm{L}}^{*}$ is oxidised at $E>0.3 \mathrm{~V}$ in a clear correlation with the $\mathrm{CO}$ stripping voltammogram depicted in Fig. 9a (the difference in the potentials has to be related to the different techniques used in the experiments carried out by FTIRS and cyclic voltammetry: stepping and sweeping potential respectively, even though the effective potential sweep rates are similar).

A linear Stark tuning shift of the $\mathrm{CO}$ stretching frequency with applied potential is observed for $\mathrm{CO}_{\mathrm{L}}$ and $\mathrm{CO}_{\mathrm{B}}$ with slopes of 37 and $36 \mathrm{~cm}^{-1} \mathrm{~V}^{-1}$, respectively. Similar Stark tuning slopes for $\mathrm{CO}_{\mathrm{L}}$ and $\mathrm{CO}_{\mathrm{B}}$ were found in a previous study of $\mathrm{CO}$ adsorption and oxidation on $\mathrm{Pt}(110)$ in acidic solution [45].

As can be observed in the spectra, the oxidation of $\mathrm{CO}_{\mathrm{B}}$ occurs at lower potentials than the oxidation of $\mathrm{CO}_{\mathrm{L}}$, and the band intensity as well as the band position does not depend on the annealing method, suggesting that this oxidation peak is not very sensitive to the surface order. However, the band related to the $\mathrm{CO}$ adsorbed on top sites is more significantly affected by the employed annealing treatment. Two important characteristics are the high potential oxidation of the $\mathrm{CO}_{\mathrm{L}}$ on the $\mathrm{Pt}(110)$ annealed in $\mathrm{H}_{2} / \mathrm{Ar}$, in agreement with the $\mathrm{CO}$ stripping voltammogram of Fig. 7, and the increase in the intensity of the band at $1,955 \mathrm{~cm}^{-1}$ when the annealing is carried out in $\mathrm{I}_{2}$. The latter suggests shorter terraces or higher step density (i.e. conversion from $\mathrm{CO}_{\mathrm{L}} \rightarrow \mathrm{CO}_{\mathrm{L}}^{*}$ ) when the electrode is cooled down in $\mathrm{I}_{2}$ atmosphere than annealed in $\mathrm{H}_{2} / \mathrm{Ar}$ gases. This fact could be related to the high mobility of the lowcoordinated $\mathrm{Pt}$ atoms present on the missing row, a mobility induced by the $\mathrm{CO}_{\mathrm{ads}}$ oxidation that results in the faceting of the surface as was described earlier in UHV [48].

\section{Conclusion}

In this work, we presented a study on the electrooxidation of $\mathrm{CO}$ on $\operatorname{Pt}(100)$ and $\operatorname{Pt}(110)$ single crystal 
electrodes in alkaline media and the effect of different surface preparations of the $\operatorname{Pt}(100)$ and $\operatorname{Pt}(110)$ surface on the CO adsorption and oxidation.

As in the case of acidic media [13-15], we found that the $\mathrm{Pt}(100)$ and $\mathrm{Pt}(110)$ present significant differences in the blank voltammogram in alkaline media as a function of the annealing treatment.

For the oxidation of $\mathrm{CO}$ adsorbed on the $\operatorname{Pt}(100)$, it was found that the $\mathrm{CO}$ oxidation takes place at low potentials on a surface with lower superficial order. Using FTIR, two different adsorption sites were identified on the $\operatorname{Pt}(100)$ regardless of the treatment employed: linearly bonded $\mathrm{CO}\left(\mathrm{CO}_{\mathrm{L}}\right)$ and bridged bonded $\mathrm{CO}$ $\left(\mathrm{CO}_{\mathrm{B}}\right)$. In contrast with the observations in acidic media [34], the predominant adsorbate in alkaline media was the $\mathrm{CO}_{\mathrm{B}}$ for all surfaces. The contribution of $\mathrm{CO}_{\mathrm{L}}$ is more significant for the surface with lower superficial order (i.e. the one cooled down in Ar).

The $\mathrm{CO}$ oxidation depends strongly on the surface preparation of the $\operatorname{Pt}(110)$. The broad feature in the oxidation of $\mathrm{CO}$ when the surface was cooled down in air suggests a large distribution of terraces sites. When the electrode was flame annealed and cooled down in a $\mathrm{H}_{2} / \mathrm{Ar}$ saturated atmosphere, the stripping voltammogram shows two well-defined peaks that can be associated to the oxidation of $\mathrm{CO}$ at the terrace sites with $(1 \times 1)-\mathrm{Pt}(110)$ and steps sites, respectively. When the electrode was cooled down in $\mathrm{I}_{2}$, the peak associated to the $\mathrm{CO}$ oxidation on defect sites is well resolved, is slightly shifted to positive potentials and has a higher charge. Voltametric and FTIR results suggest that $\mathrm{CO}$ adsorbed on the low coordinated platinum atoms is the least reactive.

Using FTIR, three different adsorptions sites were found on the $\operatorname{Pt}(110)$, i.e. $\mathrm{CO}_{\mathrm{L}}, \mathrm{CO}_{\mathrm{L}}^{*}$ and $\mathrm{CO}_{\mathrm{B}}$. The $\mathrm{CO}$ linearly bonded $\left(\mathrm{CO}_{\mathrm{L}}\right)$ and $\mathrm{CO}$ bridged bonded $\left(\mathrm{CO}_{\mathrm{B}}\right)$ appear in the spectra regardless the treatment employed; however, the intensity of the bands depends strongly on the cooling treatment. The predominant adsorbate in alkaline media was the $\mathrm{CO}_{\mathrm{L}}$ for all three cooling methods employed. The contribution of $\mathrm{CO}_{\mathrm{B}}$ is more significant for the surfaces with lower superficial order (i.e. the ones cooled down in air and $\mathrm{I}_{2}$ vapor). Additionally, the identification of $\mathrm{CO}_{\mathrm{L}}^{*}$ strongly adsorbed on low coordinated atoms was supported by FTIR, by a band at $1,955 \mathrm{~cm}^{-1}$. It was observed that the band intensity related to $\mathrm{CO}_{\mathrm{L}}^{*}$ decreases at potentials higher than $0.3 \mathrm{~V}$, which is about $0.15 \mathrm{~V}$ more positive than the observed for $\mathrm{CO}_{\mathrm{L}}$, suggesting a lower reactivity of $\mathrm{CO}_{\mathrm{L}}^{*}$. Finally, it is possible to suggest a mechanism in which at the initial potential $(0.05 \mathrm{~V}), \mathrm{CO}_{\mathrm{L}}$ is adsorbed at two different sites, i.e. $\mathrm{CO}_{\mathrm{L}}$ adsorbed on terraces with $(1 \times 2)-\mathrm{Pt}(110)$ and $\mathrm{CO}_{\mathrm{L}}^{*}$ adsorbed on the missing row step, with the $\mathrm{CO}_{\mathrm{L}}$ being more reactive than the $\mathrm{CO}_{\mathrm{L}}^{*}$.
Acknowledgements This work was funded by The Netherlands Organization for Scientific Research (NWO) through a "VICI" grant awarded to M.T.M.K. The authors also acknowledge the support of the European Commission through the FP7 Initial Training Network "ELCAT" (grant agreement no. 214936-2).

Open Access This article is distributed under the terms of the Creative Commons Attribution Noncommercial License which permits any noncommercial use, distribution, and reproduction in any medium, provided the original author(s) and source are credited.

\section{References}

1. N.P. Lebedeva, M.T.M. Koper, E. Herrero, J.M. Feliu, R.A. van Santen, J. Electroanal. Chem. 487, 37-44 (2000)

2. N. Hoshi, M. Tanizaki, O. Koga, Y. Hori, Chem. Phys. Lett. 336, 13-18 (2001)

3. N.P. Lebedeva, M.T.M. Koper, J.M. Feliu, R.A. van Santen, J. Electroanal. Chem. 524-525, 242-251 (2002)

4. N.P. Lebedeva, M.T.M. Koper, J.M. Feliu, R.A. van Santen, J. Phys.Chem. B 106, 12938-12947 (2002)

5. D.S. Strmcnik, D.V. Tripkovic, D. van der Vliet, K. Chang, V. Komanicky, H. You, G. Karapetrov, J.P. Greeley, V.R. Stamenkovic, N.M. Markovic, J. Am. Chem. Soc. 130, 15332-15339 (2008)

6. F.J. Vidal-Iglesias, J. Solla-Gullón, J.M. Campiña, E. Herrero, A. Aldaz, J.M. Feliu, Electrochimica Acta 54, 4459-4466 (2009)

7. J. Spendelow, G.Q. Lu, P.J.A. Kenis, A. Wieckowski, J. Phys. Chem. B 110, 9545-9555 (2006)

8. G. García, M.T.M. Koper, Phys. Chem. Chem. Phys. 10, 38023811 (2008)

9. G. García, M.T.M. Koper, J. Am. Chem. Soc. 131(15), 5384-5385 (2009)

10. G. García, M.T.M. Koper, Phys. Chem. Chem. Phys. 11, 1143711446 (2009)

11. J. Clavilier, R. Faure, G. Guinet, R. Durand, J. Electroanal. Chem. 107, 205 (1980)

12. J. Clavilier, J. Electroanal. Chem. 107, 211 (1980)

13. J. Clavilier, J.M. Orts, J.M. Feliu, J. Phys. IV 4 (1994)

14. J.M. Feliu, A. Rodes, J.M. Orts, J. Clavilier, Pol. J. Chem. 68, 1575-1595 (1994)

15. L.A. Kibler, A. Cuesta, M. Kleinert, D.M. Kolb, J. Electroanal. Chem. 484, 73-82 (2000)

16. A. Al-Akl, G.A. Attard, R. Price, B. Timothy, J. Electroanal. Chem. 467, 60-66 (1997)

17. D. van der Vliet, M.T.M. Koper, Surf. Sci. 604, 1912-1918 (2010)

18. G. García, P. Rodriguez, V. Rosca, M.T.M. Koper, Langmuir 25 (23), 13661-13666 (2009)

19. A.M. Bittner, J. Wintterlin, G. Ertl, J. Electroanal. Chem. 388, 225-231 (1995)

20. R. Vogel, I. Kamphausen, H. Baltruschat, Ber. Bunsenges. Phys. Chem. 96, 525 (1992)

21. J. Clavilier, D. Armand, S.G. Sun, M. Petit, J. Electroanal. Chem. 205, 267 (1986)

22. F.J. Vidal-Iglesias, N. García-Aráez, V. Montiel, J.M. Feliu, A. Aldaz, Electrochem Comm 5(1), 22-26 (2003)

23. J. Kollár, L. Vitos, B. Johansson, H.L. Skriver, Phys Stat. Sol. 217, 405-418 (2000)

24. K. Mikita, M. Nakamura, N. Hoshi, Langmuir 23(17), 9092-9097 (2007)

25. C.F. McFadden, P.S. Cremer, A.J. Gellman, Lagmuir 12(10), 2483-2487 (1996)

26. I. Villegas, M. Weaver, J. Chem. Phys. 101(2), 1648-1660 (1994)

27. A. Rodes, R. Gómez, J.M. Feliu, M.J. Weaver, Langmuir 16, 811816 (2000) 
28. M. Wakisaka, T. Ohkanda, T. Yoneyama, H. Uchida and M. Watanabe (2005) Chem. Commun. 2710-2712

29. B. Rasch, T. Iwasita, Electrochimica Acta 35, 989-993 (1990)

30. T. Iwasita, A. Rodes, E. Pastor, J. Electroanal. Chem. 383, 181189 (1995)

31. K. Arihara, F. Kitamura, Takeo, K. Tokuda, J. Electroanal. Chem. 510, 128-135 (2001)

32. S. Yamagi shi, T. Fujimoto, Y. Inada, H. Orita, J. Phys. Chem B 109, 8899-8908 (2005)

33. R. Martin, P. Gardner, A.M. Bradshaw, Surf. Sci. 342, 69-84 (1995)

34. A. López-Cudero, A. Cuesta, C. Gutiérrez, J. Electroanal. Chem. 586, 204-216 (2006)

35. C.K. Rhee, J.M. Feliu, E. Herrero, P. Mrozek, A. Wieckowski, J. Phys. Chem. 97, 9730-9735 (1993)

36. B. Hammer, O.H. Nielsen, J.K. Norskov, Catalysis Lett. 46, 31-35 (1997)

37. G. Blyholder, J. Phys. Chem. 68, 2772 (1964)
38. M.T.M. Koper, R.A. van Santen, J. Electroanal. Chem. 476, 64 (1999)

39. C. Morallon, J. Electroanal. Chem. Interfacial Electrochem. 288, 217 (1990)

40. J. Souza-Garcia, V. Climent, J.M. Feliu, Electrochem. Commun. 11, 1515-1518 (2009)

41. E. Yeager, A. Homa, B.D. Cahan, D. Scherson, J. Vac. Sci. Technol. 20, 628-633 (1982)

42. R. Michaelis, D.M. Kolb, J. Electroanal. Chem. 328, 341-348 (1992)

43. R. Michaelis, D.M. Kolb, Surf. Sci. 234, L281-L284 (1990)

44. S.-C. Chang, M. Weaver, Surf. Sci. 238, 142-162 (1990)

45. M.T.M. Koper, R.A. van Santen, S.A. Wasileski, M.J. Weaver, J. Chem. Phys. 113, 4392 (2000)

46. S. Watanabe, J. Inukai, M. Ito, Surf. Sci. 293, 1 (1993)

47. S.R. Bare, P. Hofmann, D. King, Surf. Sci. 144(2-3), 347-369 (1984)

48. R. Ladas, Imbihl, G. Ertl, Surf. Sci. 198, 42-68 (1988) 